\title{
Catholic Churches, Sound-Reinforcement Systems and RASTI
}

\author{
AntCnio P.O. Carvalho ${ }^{\dagger}$ and Margarida M.F. Lencastre \\ Acoustics Laboratory, Department of Civil Engineering, Faculty of Engineering, University of Porto, Rua dos Bragas, \\ P-4050-123 Porto, Portugal
}

(Received 14 March 1999; accepted 4 June 1999; revised 5 February 2000)

\begin{abstract}
This paper concentrates on the Rapid Speech Transmission Index (RASTI) values within churches and on their differences with the sound-reinforcement systems (SRS) off and on. The RASTI was measured in 31 unoccupied Portuguese Catholic churches built in the last 11 centuries. Four receiver locations were used in each church, with and without the use of the SRS from the altar area. The vast majority of churches tested with the SRS off have RASTI values not greater than 0.45 giving a poor rating in the quality of speech intelligibility. It was determined that only for distances greater than about $11 \mathrm{~m}$ from the altar area is the SRS useful in increasing the RASTI values. In general, the standard SRS systems used in Portuguese churches provide an average increase of 7 per cent in the RASTI values when all receiver positions are considered. Excluding the closest position to the sound source, the average increase of the RASTI is about 19 per cent from the RASTI values measured with the SRS off.
\end{abstract}

${ }^{\dagger}$ Member of the International Institute of Acoustics and Vibration (IIAV)

\section{INTRODUCTION}

This study is part of a research program initiated in 1991 at the University of Porto (Portugal) and the University of Florida (USA). The aim of the program is to explore methods to evaluate, and compare the acoustical qualities of churches. The program involves field measurements in a very large number of Portuguese Catholic churches and has included two major components to date:

- Objective studies - Measurements of nine objective acoustical parameters at multiple locations in each church. ${ }^{1-3}$

- Subjective studies - Evaluations of live musical performances and speech intelligibility using a large sample of listeners and several locations in each church. ${ }^{2,4,5}$

This article presents a report regarding the first item and concerning the Rapid Speech Transmission Index (RASTI) measurements.

\section{METHODOLOGY}

\subsection{Method Summary}

The main research hypothesis is that the differences in the RASTI values among churches, with and without the use of their Sound-Reinforcement Systems (SRS), can be measured.

The study consisted of two parts both regarding RASTI analyses in unoccupied churches (apart from the two experimenters). The first part was to gather objective evaluations of the acoustical qualities of the churches, from the use of the RASTI, using only their own sound source at the altar area (the parameter named RASTI_SRS.off). The second part was to gather the same type of evaluations of the same sample of churches but with the use of the churches' SRS (parameter named RASTI_SRS.on). The loudspeaker arrangement commonly present in the churches tested was the distributed line source system (but with no signal-delayed), which is the standard in Portugal especially in older churches (see Fig. 1). In all the churches the pew area was hard-surfaced and sound reflecting.

The limitations using this type of methodology for evaluations were fully realised and understood. The acoustical response of a church changes when it is fully occupied (especially due to the increase of absorption in the seating area). Nevertheless this methodology gives a normalised sound environment that can be easily compared among churches.

The relative on/off performance of the acoustical environment can be compared among churches even if the SRS performance is so design-dependent as it is. This holds true in many situations because:

i) the distributed loudspeakers are usually placed vertically on a wall (or column) facing the opposite reflecting wall and not directed down to the pew area (that can be increasingly absorptive when the number of occupants increases);

ii) the majority of religious services in churches are now held with only a few persons, who do not cover most of the reflecting pew area (Sunday services are the exceptions).

Therefore, as the percentage of the seating area occupied by a congregation increases, the less useful the results of this study become. For these reasons, the data of this study should not be extrapolated to a fully occupied church or when it has a non-reflecting pew area.

For the RASTI measurement in each church, the transmitter location was in front of the main altar at about $1.65 \mathrm{~m}$ above the floor to represent a standardised speech situation during services. The sound level of the source was set to $+10 \mathrm{~dB}$ compared with the RASTI standard level due to the large volume of some of the churches. ${ }^{6}$ Four positions in each church were used for the receiver location (named $A, B$, $C$ and $D$ as seen in Fig. 2). In each receiver position three or four RASTI measurements were taken and then averaged to give the RASTI value at that location. All the statistical analyses were done using the SYSTAT ${ }^{\circledR}$ software. 